this nature is a fine example of what the late Sir Thomas Lewis, the master pioneer in electrocardiography, has termed 'clinical science'. 'The boundaries between individual sciences may not be maintained without hindering progress; overlaps between Clinical Science, pathology and physiology are vital to medical science as a whole; they bind together three activities which in process of time have grown too far apart from one another"s.

${ }^{1}$ Wilson, McLeod, Barker and Johnston, Amer. Heart J., 10, 46 (1934),

"A very clear discussion of the subject is found in Ashman and Hull, "Essentials of Electrocardiography" (2nd edit., Macmillan, New York, 1941).

- Ashman, Byer and Bayley, Amer. Heart J., 25, 16 (1943). Ashman and Byer, ibid., 36. Ashman, Gardberg and Byer, ibid., 26, 473 (1943).

"Master, "The Electrocardiogram and X-Ray Configuration of the Heart" (Lea and Febiger, Philadelphia, 1939).

s Benatt and Berg, Amer. Heart $J$., in the press.

'Clifford-Jones and MacDonald, Tubercle, 24, 6 (1943).

${ }^{7}$ Ashman, Amer. Heart J., 26, 495 (1943).

- Lewis, Sir Thomas, Brit. Med. J., 30, 3 (1935).

\section{REPEATING COMPASSES}

\section{By W. E. MAY}

$\mathrm{F}$ ROM time to time paragraphs appear in the Press on the subject of compasses in aircraft. They usually take the form of a complaint of the inaccuracy of magnetic compasses in general, followed by praise of some invention which is said to surmount all difficulties. The new instrument is often improperly described as a 'gyro-compass'. It is not the purpose of this article to advertise or condemn any of these inventions, but to enable the reader to see in proper perspective the claims which they contain.

For nearly a century, inventors have striven to perfect a repeating magnetic compass, that is to say, a compass the indications of which are automatically transmitted to a point or points at some distance. Many methods of obtaining signals from an ordinary magnetic compass in order to work a repeater system have been tried. Among these may be mentioned the forms using selenium cells, intermittent positive contact between contact on the card and in the bowl, or a Wheatstone bridge principle using electric currents passed through the liquid in the bowl. All need some form of signal amplification which may be obtained by the use of valves or relays.

When we talk of a magnetic compass we are apt to think only of the ordinary instrument containing a needle which aligns itself with the direction of the lines of magnetic force; but there is a second type which particularly lends itself to the provision of a repeating system. That is the earth inductor or rotating inductor compass, which depends on the principle that if an armature, similar to that of a small electric motor, is rotated about a vertical axis in the earth's magnetic field, it generates a current. This current can be tapped off in the ordinary way by means of a commutator and brushes, the strength and direction of the current in the external circuit being determined by the orientation of the brushes relative to magnetic north. There will be a relative brush position where no current flows in the external circuit.

Thus by various means both the needle and earth inductor types of repeating compass give a signal as soon as the bowl (or other follow-up unit such as the brush carriage) is out of step with the directional element. This signal can be made use of in two ways. In the simple form the bowl is turned by means of a Bowden wire to the position corresponding to the course desired. When the aircraft is off her course, a simple indicator shows the pilot which way to steer to get back.

In the more ambitious arrangement, the directional signal is used to control a follow-up motor which drives the bowl round until the position of 'no signal' is reached. At the same time it drives a step-by-step transmitter through gearing, and this transmitter drives the repeaters electrically so that they indicate the orientation of the bowl and consequently the course of the aircraft.

Another type of repeating compass may be styled the static inductor type. In this type an alternating electric current is passed through a coil wound on an iron alloy core bent into a triangle or other shape. This core is fixed in the aircraft. with its plane horizontal. According to the course of the aircraft, the various sides of the core will be magnetized in a greater or less degree by the magnetism of the earth. The fact that the sides thus become magnets of differing strengths upsets the balance of the alternating currents in the parts of the coil wound round them, thereby causing varying currents to flow in wires which are tapped off the coil at intervals. These tappings are led to coils in the repeater where they set up a magnetic field. A magnetic needle lines itself up with this field and thus indicates the course of the aircraft.

A combination of the needle and static inductor type of compass is also sometimes used. This is similar to the static inductor type, but contains in addition an ordinary compass needle of rather high magnetic moment. The needle points to magnetic north and also serves to induce magnetism in the core of the inductor.

A type of compass which is often referred to nowadays is the gyro-compass. This compass depends on the fact that a perfectly balanced gyroscope will always tend to keep its axis pointing in a fixed direction in space. This of itself would be of little value as a direction indicator, since the earth's rotation will produce a continuous variation in the direction of the axis relative to the meridian. The gyroscope can, however, be made to act as a compass by the introduction of some form of control, so that this fixed direction in space is amended until the axis is horizontal and pointing along the meridian. In the true gyro-compass, this is effected by using the rotation of the earth to harness the force of gravity to the gyroscope.

The arrangement is perfectly satisfactory in a ship of moderate size, but in aircraft the higher speeds and greater manœuvrability produce accelerations introducing a varying false vertical and upsetting the control. All attempts to use gyro-compasses in aircraft have consequently been failures.

The gyroscope, as distinct from the gyro-compass, has, however, a use in aircraft. We have not been able to produce a gyroscope so well made that it will give a perfect performance with its axis maintaining a fixed direction in space indefinitely, but wo can make one which will maintain its direction for a matter of minutes. It will be appreciated that having no gravity control, this gyroscope will be unaffected by the movement of the aircraft. If now we link any form of repeating magnetic compass to this gyroscope, so that the latter is controlled by the former, the gyroscope will tend to line itself up with the magnetic compass; but as its rate of precession is much less than the rate of oscillation of the compass, 
it will actually line itself up to the mean direction of that instrument. In this way, by using a magnetic compass to control a gyroscope and the gyroscope to control repeaters we get a combination, known as a 'gyro-magnetic compass', which smoothes out most of the erratic oscillation of the ordinary compass.

Ancther application of the gyroscope is sometimes used. In those static inductor compasses where the core is magnetized by a compass needle, it is convenient to use a double-axis needle, that is, one which is mounted on a vertical axis instead of being free to dip as in the ordinary compass. This method of mounting introduces difficulties, because if accelerations cause the axle to leave the vertical, the vertical force of the earth pulls down on the north end of the needle, thereby deflecting it from north and causing an error. By introducing a gyroscope into the instrument it is possible to use the gyroscope to stabilize it so that the axle of the needle will always remain truly vertical.

When speaking of gyro-magnetic compasses it must be clearly understood that they are fundamentally magnetic compasses and not gyro-compasses. Although they have the advantage of smoothing out oscillations, they still point to the magnetic and not to the true north. The master compass must be fitted in a position as remote as possible from magnetic disturbance. The aircraft must be 'swung' to adjust the compass in the ordinary way, and rather more than ordinary care is required to do this effectively. Finally, a deviation table must be obtained and the deviations applied to all repeaters when using them.

The statement that the gyro-magnetic compass indicates the magnetic rather than the true north must be qualified. In some systems a variationsetting corrector or other device is provided. This is a link in the repeater system which enables the repeaters to be put out of step with the master in a convenient manner. If the variation is kept set on this device, the repeaters will show a heading differing from true by the deviation. If the variation plus deviation is kept set, the repeaters can be made to indicate true north, but it will be noted that this does not mean that the swinging of the aircraft for compass adjustment can be dispensed with.

We can now summarize the several points to be considered when judging the relative advantages of the various systems. They are : (1) A needle compass is liable to be affected by accelerations and movements of the aircraft, that is, by swirl error, northerly turning error, etc. (2) All types of magnetic compasses, whether they be needle or inductor or a combination of both, indicate the direction of the magnetic field at the compass position, and not necessarily the magnetic meridian. It follows that they all have deviations which must be allowed for or corrected. (3) Repeating compasses can be placed in better positions from the magnetic point of view than those positions from which the aircraft is controlled. (4) In repeaters other than those driven on the step-by-step principle, the needle is apt to be made to oscillate by shocks and accelerations. The repeaters, however, are self-synchronous so do not need lining up when the compass is switched on. (5) Inductor compasses are less sensitive than needle compasses. (6) Gravity controlled gyro-compasses cannot be used in aircraft. (7) Gyro-magnetic compasses require adjusting like any other magnetic compasses, but smooth out swirl and northerly turning errors. (8) The introduction of a gyro introduces an additional electrical complication.

\section{OBITUARIES}

\author{
Mr. C. S. Middlemiss, C.I.E., F.R.S.
}

WrTH the death on June 11, 1945, at Tunbridge Wells, at the age of eighty-five, of Mr. Charles Stewart Middlemiss, Indian geology has lost its doyen one who will long be regarded as one of the great figures of Indian geology. Middlemiss was the sor of Robert Middlemiss of Hull, where he was borr. on November 22, 1859. He was educated at Caistor and St. John's College, Cambridge, taking his B.A degree in 1881. He joined the Geological Survey of India on September 20, 1883, when H. B. Medlicott was still head of the Department.

During his service, Middlemiss did field work in the Himalaya, the Salt Range, and Hazara, all in north-western India; in Coimbatore, Salem and the Vizagapatan Hill Tracts in the Madras Presidency; in the Southern Shan States and Karenni in Burma; in Central India, Rajputana and North Bombay (Idar); and finally in Kashmir. He also investigated the earthquakes of Bengal (1885), Kangra (1905), and Calcutta (1906). During spells at headquarters he was curator of the Geological Museum (1898-99), and in charge of the headquarters office (1907-8). $\mathrm{He}$ was promoted deputy superintendent in 1889 and superintendent in 1895. He officiated as director for two periods, during 1914-15 and in 1916. In 1903 he paid a visit to Ceylon on deputation.

Middlemiss should have retired from the Geological Survey of India on reaching the age of fiftyfive in 1914, but on account of the War his service was extended so that he did not leave the Department until April 1, 1917, after being gazetted C.I.E. in 1916. As a result of this extension, Middlemiss holds the record for length of service in the Geological Survey, amounting to 33 years 6 months and 11 days (beating Medlicott by five months and eight days). Having created this record, Middlemiss then entered the service of the Maharaja of Kashmir, with the title of superintendent, Mineral Survey, Jammu and Kashmir, from which he did not retire until his seventy-first year in 1930, after a total service in India of more than forty-six years.

Of other scientific activities, we may record that Middlemiss became an ordinary and life member of the Asiatic Society of Bengal in 1884, and a fellow in 1912, being at the time of his death the senior member of the Society by four years and also the senior fellow. He became a fellow of the Geological Society of London in 1900 , and was awarded the Lyell Medal in 1914. Middlemiss was elected a fellow of the Royal Society in 1921. He was president of the Geological Section of the Fourth Indian Science Congress at Bangalore in 1917 and president of the Ninth Indian Science Congress at Madras in 1922. He was also president of the Mining and Geological Institute of India in 1928.

Middlemiss married Martha Frances Wheeler, daughter of Major-General Wheeler, of the Bengal Staff Corps. They had five sons and one daughter, of whom two sons died early in India, and two sons lost their lives in the War of 1914-18, in Gallipoli and France respectively. On retiring from India, Middlemiss settled down at Crowborough in Sussex where he became a centre of local activities. Mrs. Middlemiss died in 1931.

Middlemiss, as first known to my contemporaries and $m e$, was already in the forties-partially bald with an aureole of grey hair, bright blue eyes, pleasant 